\title{
Insights into the synthesis of poly(ethylene 2,5-furandicarboxylate) from 2,5-furandicarboxylic acid: steps toward environmental and food safety excellence in packaging applications.
}

Maria Barbara Banella, ${ }^{a}$ Jacopo Bonucci, ${ }^{a}$ Micaela Vannini, ${ }^{a *}$ Paola Marchese, ${ }^{a}$ Cesare Lorenzetti ${ }^{b}$ Annamaria Celli, ${ }^{\mathrm{a}}$

${ }^{a}$ Department of Civil, Chemical, Environmental and Materials Engineering, University of Bologna, Via Terracini 28, 40131 Bologna, Italy

${ }^{\mathrm{b}}$ Tetra Pak Packaging Solutions AB, Ruben Rausing Gata, SE-221 86 Lund, Sweden

*corresponding Author (email address: micaela.vannini@ unibo.it) 
Figure S1: DSC curves of all the PEF samples prepared by direct melt polycondensation

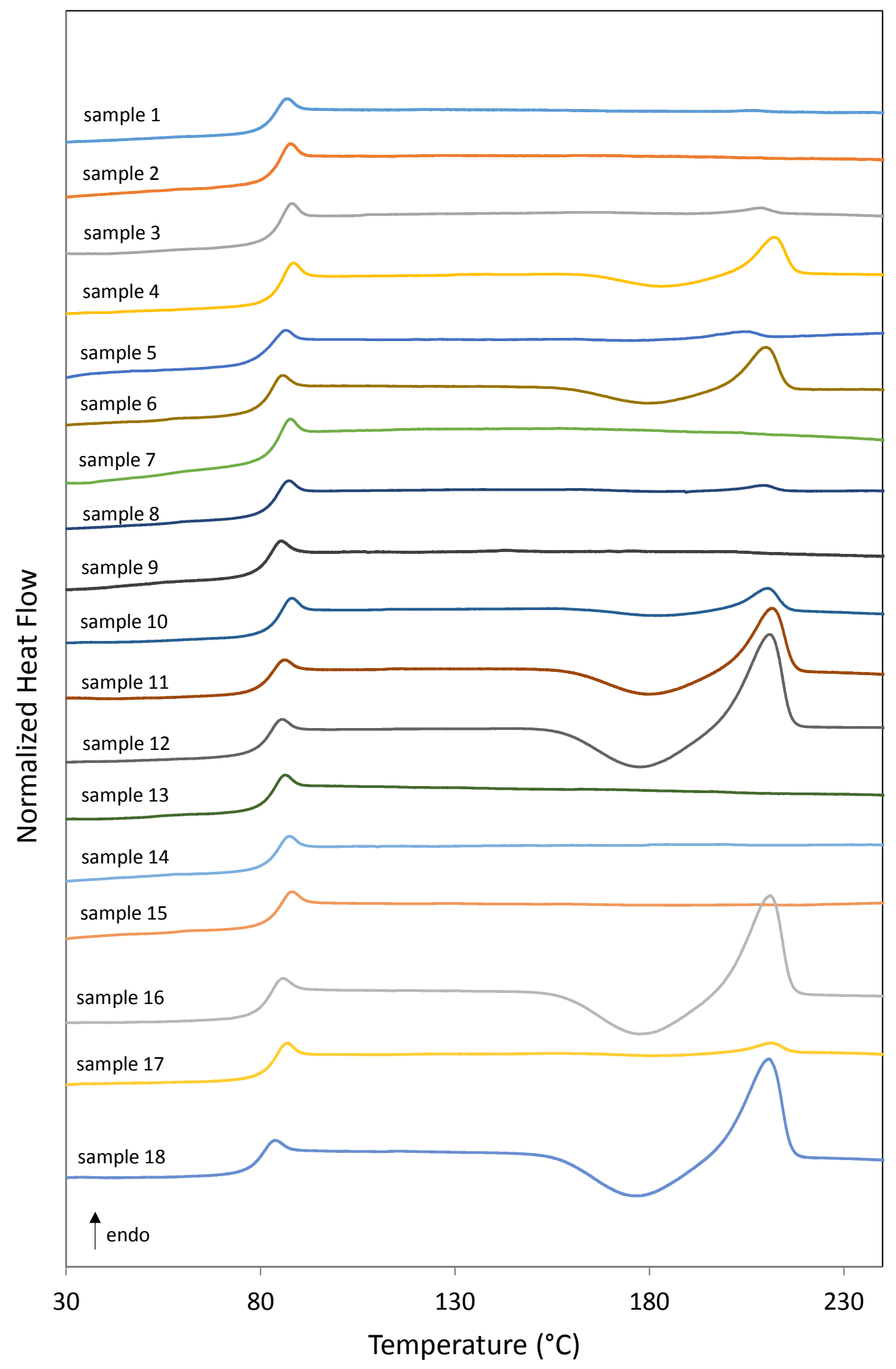


Figure S2: DSC curves of the sample 7 (PEF prepared with $\left.\mathrm{Al}(\mathrm{acac})_{3}\right)$ undergone to SSP

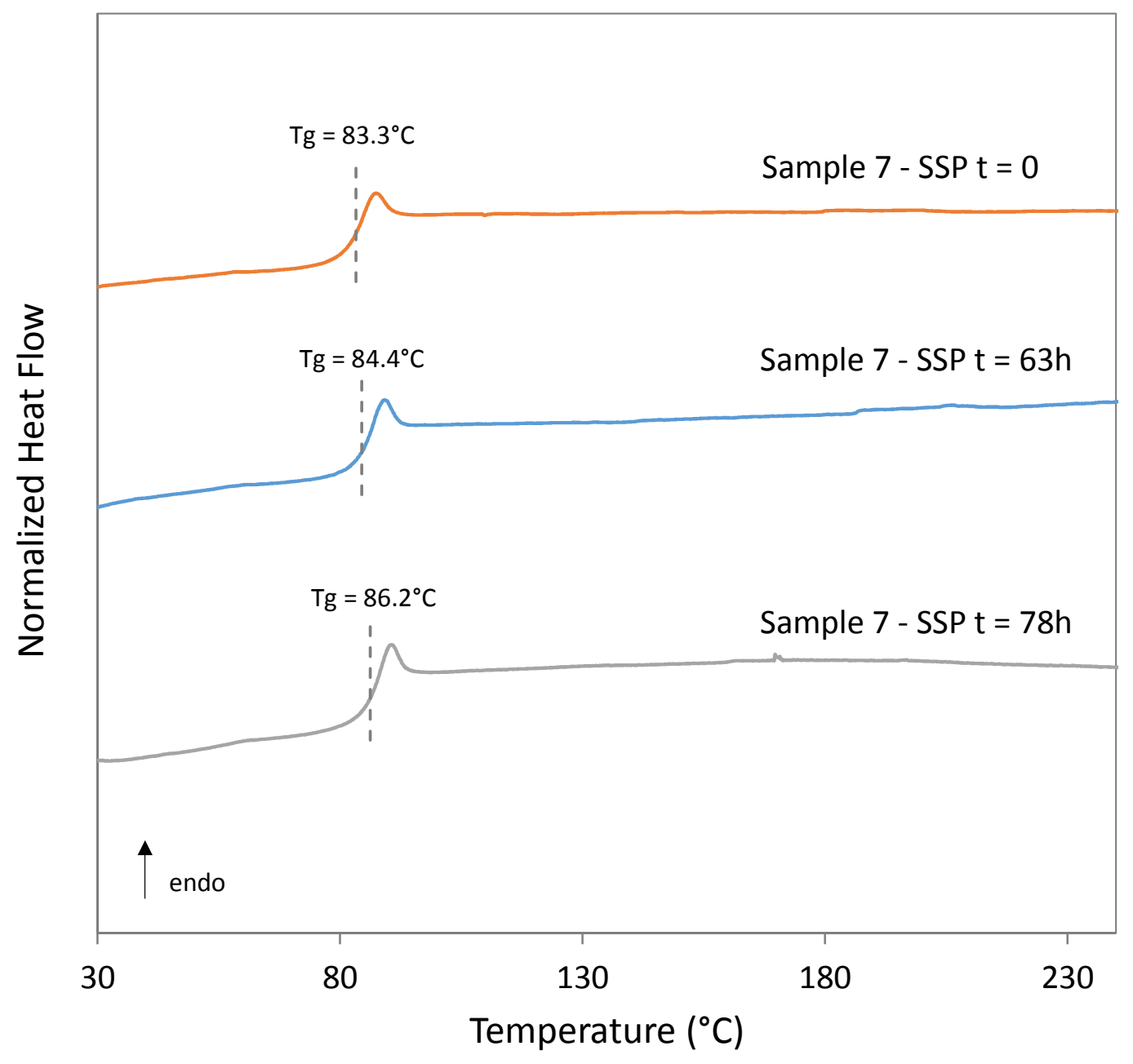


Figure S3: FT-IR spectra of PEF samples prepared with the three catalysts (TBT, ZnAcO and $\left.\mathrm{Al}(\mathrm{acac})_{3}\right)$ in different amounts ( 400 and 50 ppm), recorded by using the FT-IR Perkin Elmer Spectrum One, with ATR equipment

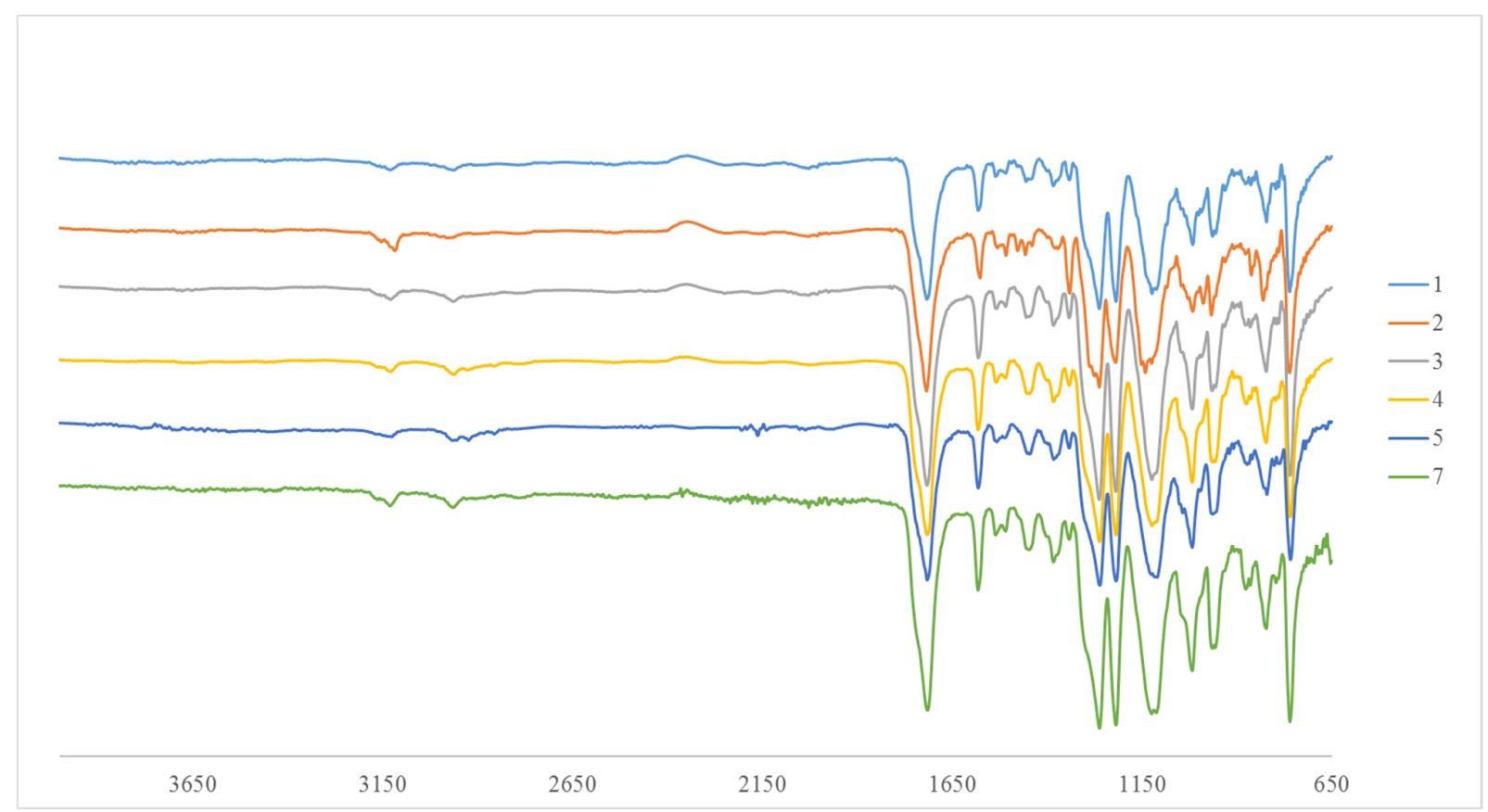

